\section{Native Trees, Shrubs, and Vines: A Guide to Using, Growing, and Propagating North American Woody Plants}

\section{William Cullina}

Houghton Mifflin, 356 p, 200 color photographs, hardcover, 2002, ISBN 0-61809-858-5, US\$ 40.

W hat do you seek in a reference book? I'm looking for good information. The information should be up-to-date and accurate. If I am to buy the book, the information also needs to be available nowhere else or in a form that is easier to use than books I already have. It is a bonus if the author writes intelligently from personal experience. Bill Cullina has met my requirements with this native woodies book.

I first met Bill Cullina when he was head propagator and manager at Niche Gardens, a primarily native plants nursery in Chapel Hill, North Carolina. For years now he has been nursery manager and head propagator at Garden In The Woods, home of the New England Wild Flower Society in Massachusetts. A few years ago he drew on his experience and that of others at NEWFS to produce the most comprehensive and user-friendly wildflower propagation book on the market. Bill's most recent book is based on his personal experience as well as research and is just as good as the wildflowers book.

I bought the woodies book based on what I saw in Bill's wildflower book. It did not disappoint me. As a Frances Tenenbaum Book, it is beautifully illustrated with quality photographs. More important, it fulfills my needs for a comprehensive source of propagation and cultural information about native woody plants- 142 genera with many more species from across the country are covered with sound and practical cultural and propagation information on each. Bill also talks about attracting wildlife and restoring habitats through the use of native woody plants, plus he suggests where

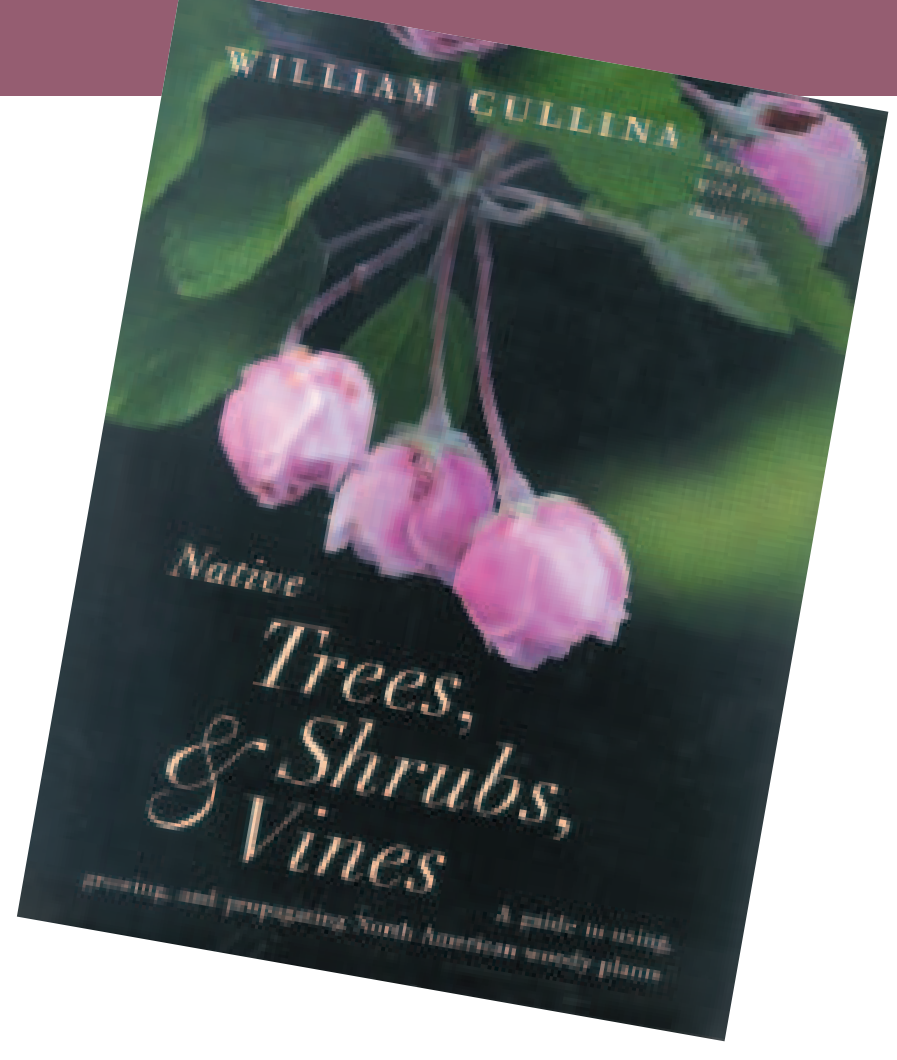

you can find many of the plants he writes about. As author of a similar regional text, I know how daunting Bill's nationwide challenge was and I applaud him for meeting it.

Bottom line? Buy this book! The review copy has created space in my home library because I was able to move multiple similar but less complete texts to the research station library. The copy of this book that I bought initially remains within arm's reach for reference in my university office. When I get called for "expert" advice, both of Bill Cullina's books are among those I turn to first.

\section{- Richard Bir}

Dick Bir is an Extension Specialist-Nursery Crops with North Carolina State University. Since 1979 he has been located at the Mountain Horticultural Crops Research Station in Fletcher, where he does research and works with both extension agents and nurseries to find better ways to propagate and grow plants. He is immediate past president of the International Plant Propagators Society-Eastern Region and author of the book Growing and Propagating Showy Native Woody Plants. 